\title{
Robin sequence-oligodactyly syndrome
}

INSERM

\section{Source}

INSERM. (1999). Orphanet: an online rare disease and orphan drug data base. Robin sequence-oligodactyly syndrome. ORPHA:3104

Robin sequence-oligodactyly syndrome is a rare, genetic, developmental defect during embryogenesis syndrome characterized by Robin sequence (i.e. severe micrognathia, retrog lossia and U-shaped cleft of the posterior palate) associated with pre- and postaxial oligodactyly. Facial features can include a narrow face and narrow lower dental arch. Clinodactyly, absent phalanx, metacarpal fusions, and hypoplastic carpals have also been reported. There have been no further descriptions in the literature since 1986. 